\title{
ORIGINAL ARTICLE Calcium signalling links MYC to NUAK1
}

\author{
T Monteverde $^{1}$, J Tait-Mulder ${ }^{1}$, A Hedley ${ }^{2}$, JR Knight $^{2}$, OJ Sansom ${ }^{1,2}$ and DJ Murphy ${ }^{1,2}$
}

NUAK1 is a member of the AMPK-related family of kinases. Recent evidence suggests that NUAK1 is an important regulator of cell adhesion and migration, cellular and organismal metabolism, and regulation of TAU stability. As such, NUAK1 may play key roles in multiple diseases ranging from neurodegeneration to diabetes and metastatic cancer. Previous work revealed a crucial role for NUAK1 in supporting viability of tumour cells specifically when MYC is overexpressed. This role is surprising, given that NUAK1 is activated by the tumour suppressor LKB1. Here we show that, in tumour cells lacking LKB1, NUAK1 activity is maintained by an alternative pathway involving calcium-dependent activation of PKCa. Calcium/PKCa-dependent activation of NUAK1 supports engagement of the AMPK-TORC1 metabolic checkpoint, thereby protecting tumour cells from MYC-driven cell death, and indeed, MYC selects for this pathway in part via transcriptional regulation of PKCa and ITPR. Our data point to a novel role for calcium in supporting tumour cell viability and clarify the synthetic lethal interaction between NUAK1 and MYC.

Oncogene (2018) 37, 982-992; doi:10.1038/onc.2017.394; published online 6 November 2017

\section{INTRODUCTION}

NUAK1, also known as ARK5, is one of 12 kinases related by sequence homology to the catalytic a-subunits of the metabolic regulator AMPK. ${ }^{1}$ Perturbation of NUAK1 has revealed a diverse array of phenotypes, pointing to roles for NUAK1 in regulating cell adhesion, $^{2}$ directional migration, ${ }^{3,4}$ neuronal axon branching, ${ }^{5}$ glycogen synthesis, ${ }^{6}$ replicative senescence ${ }^{7}$ and TAU stabilization. ${ }^{8}$ Overexpression of NUAK1 is associated with poor prognosis in multiple cancers, including colorectal, ${ }^{9}$ (Port, et al., personal communication) ovarian, $^{10-12}$ and lung, ${ }^{13}$ among others. ${ }^{14}$ Accordingly, NUAK1 is a common target of multiple miRNAs that are frequently lost during progression to metastatic disease. ${ }^{15-20}$ Despite the evidence that NUAK1 may contribute to multiple diseases, the signal transduction context of NUAK1 remains poorly defined.

We previously identified a role for NUAK1 in supporting viability of cancer cells when MYC is overexpressed. ${ }^{21}$ Briefly, we showed that MYC-overexpressing cells are unable to maintain energetic homoeostasis in the absence of NUAK1, in part due to a failure to efficiently activate AMPK and slow TORC1-dependent protein translation when faced with metabolic stress. NUAK1 and AMPK thus protect cancer cells from metabolic stress, which is a hallmark of most solid tumours. ${ }^{22,23}$ This tumour-promoting activity of NUAK1 and AMPK is somewhat paradoxical, given that both are activated by LKB1, an established tumour suppressor: LKB1 phosphorylates AMPKa subunits on $\mathrm{Thr}^{172}$, and NUAK1 on $\mathrm{Thr}^{211}$, within the conserved T-loop of the kinase domain. ${ }^{1,24}$ Notably, AMPKa ${ }^{\mathrm{T} 172}$ is phosphorylated by CamKK2 in response to calcium signalling, ${ }^{25,26}$ suggesting that the T-loops of these kinases may be accessible to other upstream regulators in addition to LKB1.

Here we demonstrate that NUAK1, like AMPK, is active in cancer cells in the absence of LKB1. Similar to AMPK, basal NUAK1 activity is maintained by tonic $\mathrm{Ca}^{2+}$ signalling and activity increases in response to $\mathrm{Ca}^{2+}$ mobilization. Unlike AMPK, NUAK1 does not appear to be regulated by CamKK2, but rather by $\mathrm{Ca}^{2+}$-dependent activation of PKCa. Significantly, suppression of either NUAK1 or PKCa leads to MYC-dependent cell death and MYC selects for increased $\mathrm{Ca}^{2+}$ signalling in part via transcriptional regulation of $\mathrm{Ca}^{2+}$-dependent protein kinases. Our work thus reveals a novel role for $\mathrm{Ca}^{2+}$ signalling in supporting viability of MYCoverexpressing cells via activation of PKCa and NUAK1.

\section{RESULTS}

NUAK1 is specifically required for $\mathrm{Ca}^{2+}$-dependent AMPK activity Depletion of NUAK1 impairs activation of AMPK in response to sustained MYC deregulation. ${ }^{21}$ We asked whether this requirement for NUAK1 is a general feature of AMPK regulation or rather a context-dependent event. AMPK is activated by phosphorylation of the a-subunit on Thr ${ }^{172}$ by LKB1, and activity is further enhanced upon a drop in the ATP:AMP/ADP ratio. ${ }^{27}$ Alternatively, CamKK2 can phosphorylate AMPKa Thr ${ }^{172}$ in response to calcium signalling. ${ }^{25}$ Additionally, AMPK can be activated upon direct binding of pharmacological agonists, such as salicylate or A769662. ${ }^{28}$ We therefore considered three modes of AMPK activation: indirect activation in response to energetic stress, direct activation by agonist binding and calcium-dependent activation.

In order to investigate the requirement of each mode of AMPK activation for NUAK1, we made use of a recently described highly selective NUAK1 kinase inhibitor, HTH-01-015. This molecule shows little-to-no activity towards AMPK, NUAK2 or other AMPKrelated kinases (ARKs) in vitro. ${ }^{29}$ Treatment of U2OS cells with HTH-01-015 for $1 \mathrm{~h}, 6 \mathrm{~h}$ or overnight reduced $\mathrm{Ser}^{445}$ phosphorylation of the NUAK1 substrate MYPT1 in a dose-dependent manner (Figure 1a). In contrast, acute treatment with HTH-01-015 had no effect on basal $\mathrm{Ser}^{79}$ phosphorylation of the canonical AMPK substrate, ACC. Acute activation of AMPK in U2OS cells using the direct agonist A769662, the electron transport chain inhibitor phenformin or the widely-used $\mathrm{Ca}^{2+}$ ionophore A23187, all increased phospho-ACC levels. Co-treatment with HTH-01-015 attenuated this increase in response to AMPK activation by $\mathrm{Ca}^{2+}$ and by phenformin, but not by the direct AMPK agonist A769662,

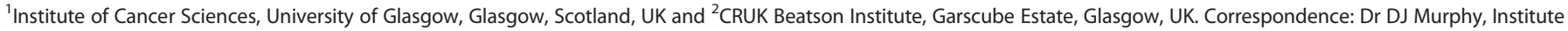
of Cancer Sciences, University of Glasgow, CRUK Beatson Institute, Garscube Estate, Switchback Rd, Glasgow G61 1BD, Scotland, UK.

E-mail: daniel.murphy@glasgow.ac.uk

Received 15 March 2017; revised 17 August 2017; accepted 15 September 2017; published online 6 November 2017 
a

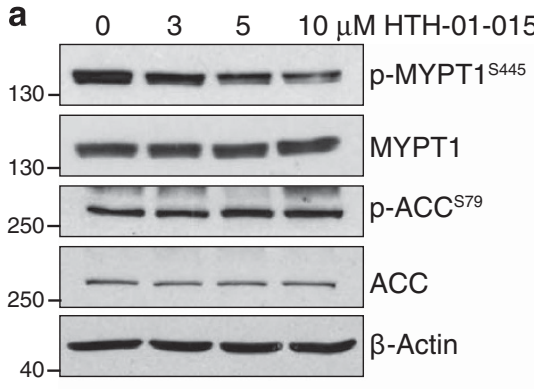

$1 \mathrm{hr}$ treatment

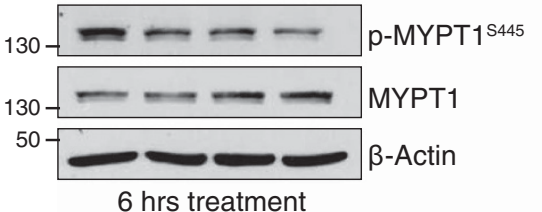

6 hrs treatment

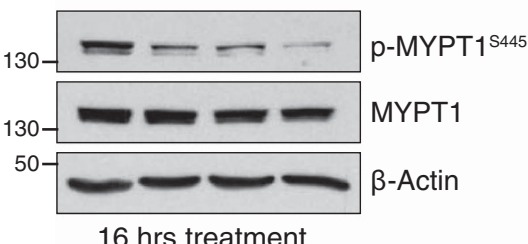

b U2OS

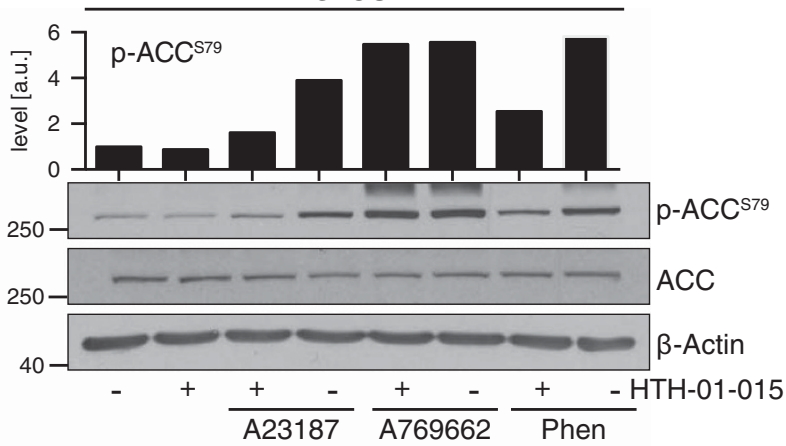

c U2OSHeLa

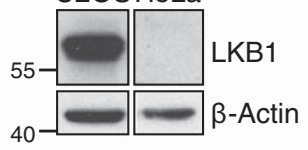

d

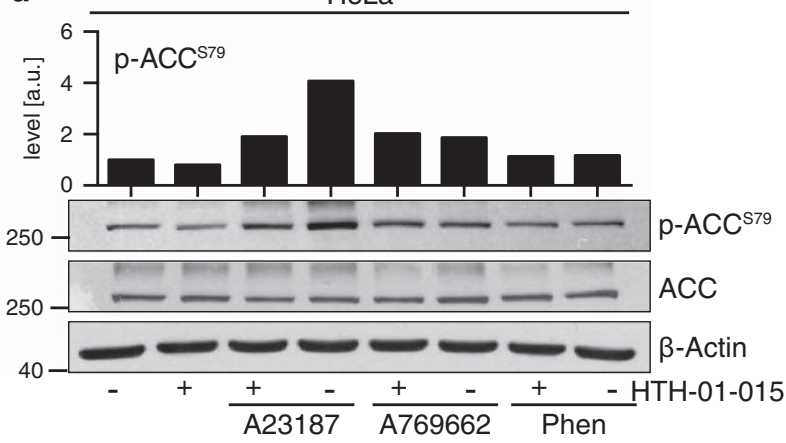

Figure 1. NUAK1 is required for calcium-dependent activation of AMPK. (a) Whole-cell extracts from U2OS cells treated with the indicated concentrations of HTH-01-015 for 1, 6 or $16 \mathrm{~h}$ and probed with the indicated antibodies. (b) Lysates from U2OS cells pre-treated with HTH-01$015 \mathrm{for} 1 \mathrm{~h}$ prior to stimulation with $3 \mu \mathrm{m}$ A23187 (10 min), $100 \mu \mathrm{m}$ A769662 (1 h) or $10 \mathrm{~mm}$ Phenformin (1 h) and blotted for phospho- and total ACC. Densitometry shows p-ACC levels in the image shown. (c) Lysates from equal numbers of U2OS and HeLa cells were probed for LKB1. Images are from the same gel and immunoblot, but rearranged to omit extraneous data. (d) Lysates from HeLa cells pre-treated with HTH-01015 for $1 \mathrm{~h}$ prior to stimulation with $3 \mu \mathrm{m} \mathrm{A23187} \mathrm{(10} \mathrm{min),} 100 \mu \mathrm{m} \mathrm{A769662} \mathrm{(1} \mathrm{h)} \mathrm{or} 10 \mathrm{~mm}$ Phenformin (1 h) and blotted for phospho- and total ACC. Densitometry shows p-ACC levels in the image shown. All images are representative of at least three independent experiments.

indicating that the requirement for NUAK1 during AMPK activation is context dependent (Figure 1b).

Suppression of $\mathrm{Ca}^{2+}$-dependent AMPK activity by $\mathrm{HTH}-01-015$ suggested that NUAK1 may be important during LKB1independent regulation of AMPK. We therefore repeated the above analysis in HeLa cells, which lack functional LKB1 (Figure 1c). As measured by ACC phosphorylation, activation of AMPK by either direct agonist or phenformin was much weaker in HeLa cells than in U2OS cells, and neither was affected by NUAK1 inhibition. In contrast, $\mathrm{Ca}^{2+}$ ionophore clearly increased AMPK activity and this increase was attenuated by NUAK1 inhibition (Figure 1d), suggesting a specific role for NUAK1 in this mode of AMPK activation.

\section{NUAK1 is activated by calcium signalling}

LKB1 is a master regulator of the AMPK-related kinases, including NUAK1. ${ }^{1}$ Our results in HeLa cells implied that NUAK1 is active in these cells despite the absence of LKB1. The myosin phosphatase targeting subunit of PP1 $\beta$, MYPT1 (PPP1R12A), is to date the bestcharacterized substrate of NUAK1 kinase activity. ${ }^{2}$ Acute treatment of HeLa cells with HTH-01-015 reduced MYPT1 phospho-Ser ${ }^{445}$ levels, suggesting that NUAK1 is indeed catalytically active in these cells (Figure 2a). Depletion of NUAK1 using two independent siRNAs also reduced phospho-MYPT1 ${ }^{\mathrm{S} 445}$, confirming the specificity of the inhibitor effect (Figure $2 b$ ). The partial reduction in phospho-MYPT1 ${ }^{\mathrm{S} 445}$ observed upon NUAK1 suppression suggested that other kinases may contribute to MYPT1 ${ }^{\mathrm{S445}}$ phosphorylation. Indeed, NUAK2, the ARK most closely related to NUAK1, was previously reported to phosphorylate this site. ${ }^{2}$ Accordingly, depletion of NUAK2 also reduced phosphoMYPT $^{\text {S445 }}$ levels, while combined suppression of both NUAK1 and 2 almost completely abolished MYPT1 ${ }^{\mathrm{S} 445}$ phosphorylation (Figure 2c). Pharmacological inhibition of both NUAK1 and NUAK2, using the dual-specificity inhibitor WZ4003 ${ }^{29}$ similarly abolished MYPT1 phosphorylation, corroborating the results of the siRNA (Supplementary Figure S1A). Thus, both NUAK1 and NUAK2 are active in HeLa cells despite their LKB1-null status.

These data indicate that NUAK1 is activated in HeLa cells by an alternative upstream kinase. We first asked if CamKK2, a known upstream activator of AMPK, might similarly activate NUAK1. Treatment of HeLa cells with the CamKK2 inhibitor STO-609 strongly suppressed phosphorylation of both $\mathrm{AMPKa}^{\mathrm{T} 172}$ and $\mathrm{ACC}^{\mathrm{S79}}$ but had no influence on phospho-MYPT1 ${ }^{\mathrm{S4} 45}$ levels (Figure 2d), suggesting that CamKK2 is not upstream of NUAK1. Strikingly, treatment with calcium ionophore A23187 increased phosphorylation of both ACC ${ }^{\mathrm{S} 79}$ and MYPT1 ${ }^{\mathrm{S} 445}$ and co-treatment with STO-609 reduced $A C C^{579}$ phosphorylation but again had no effect on phospho-MYPT1 ${ }^{\mathrm{S} 445}$, suggesting that NUAK1 is activated by a calcium-dependent kinase other than CamKK2. Accordingly, treatment of HeLa cells with two different $\mathrm{Ca}^{2+}$ ionophores, 
a

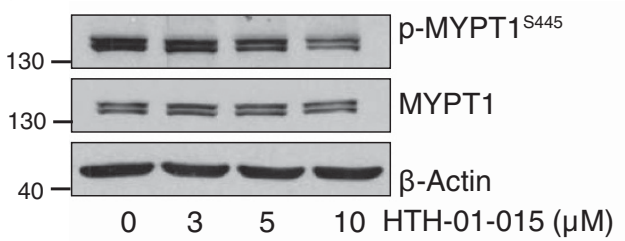

C
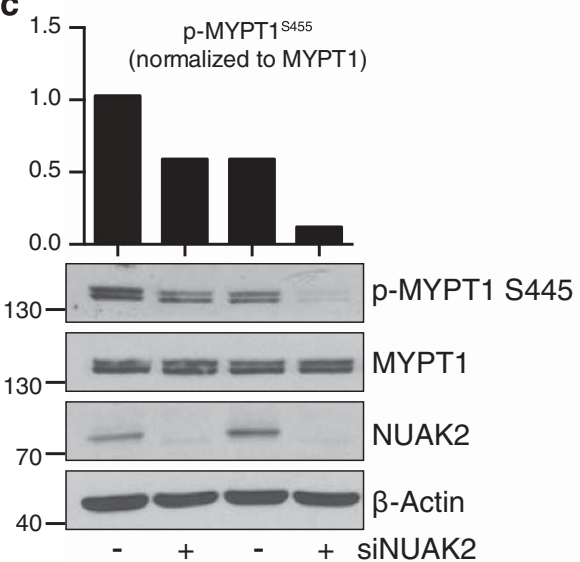

$-\quad+\quad+\quad+\mathrm{HTH}-01-015$

e

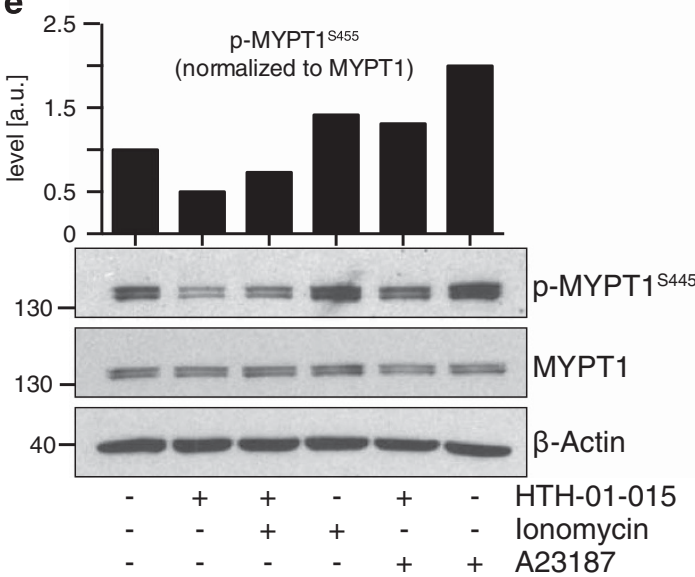

b

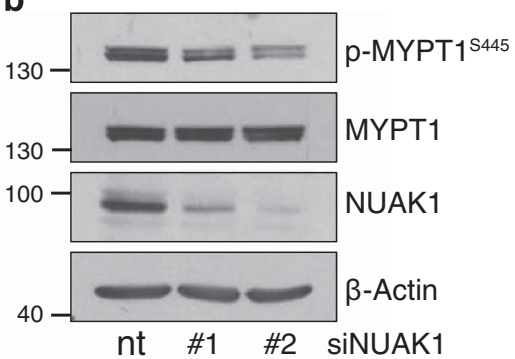

d

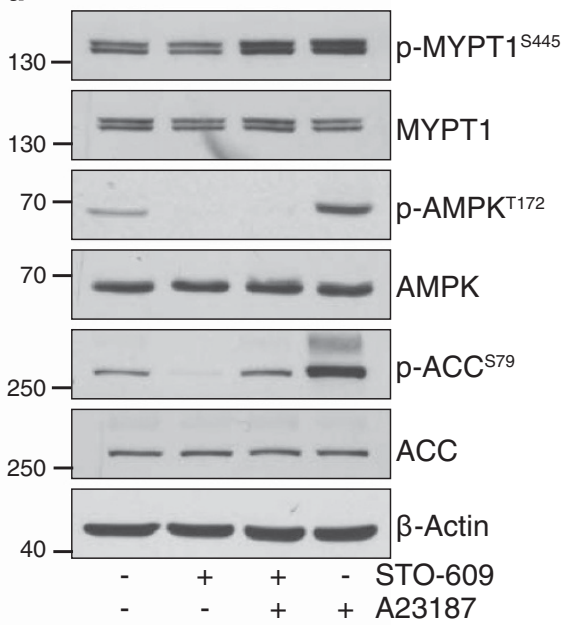

f

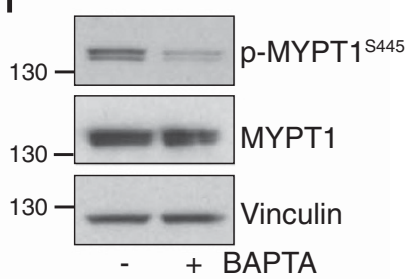

Figure 2. Calcium signalling activates NUAK1. (a) Lysates from HeLa cells treated with the indicated concentrations of HTH-01-015 for $1 \mathrm{~h}$ and probed for phospho- and total MYPT1. (b) Lysates from HeLa cells transfected with NUAK1 siRNA and probed with the indicated antibodies. nt, non-targeting control siRNA. (c) Lysates from HeLa cells transfected with NUAK2 (+) or control (-) siRNA and treated $\pm 10 \mu \mathrm{m} \mathrm{HTH-01-015,} \mathrm{as}$ indicated. Densitometry shows phospho-MYPT1 levels from the image shown. (d) Lysates from HeLa cells pre-treated with $5 \mu \mathrm{g} / \mathrm{ml}$ STO-609 for $1 \mathrm{~h}$ prior to stimulation with $3 \mu \mathrm{m} \mathrm{A23187} \mathrm{(10} \mathrm{min)} \mathrm{as} \mathrm{indicated,} \mathrm{and} \mathrm{probed} \mathrm{with} \mathrm{the} \mathrm{indicated} \mathrm{antibodies.} \mathrm{(e)} \mathrm{Lysates} \mathrm{from} \mathrm{HeLa} \mathrm{cells} \mathrm{pre-}$ treated with $10 \mu \mathrm{m} \mathrm{HTH}-01-015$ for $1 \mathrm{~h}$ prior to stimulation with $3 \mu \mathrm{m}$ A23187 or lonomycin (both 10 min) as indicated, and probed for phosphor-MYPT1. (f) Lysates from HeLa cells treated $\pm 20 \mu \mathrm{m}$ BAPTA for $30 \mathrm{~min}$. All images are representative of at least three independent experiments, except (f) where $N=2$.

lonomycin or A23187, increased MYPT1 ${ }^{\mathrm{S} 445}$ phosphorylation and this increase was attenuated by NUAK1 inhibition (Figure 2e). Conversely, treatment with the calcium chelator BAPTA strongly reduced basal levels of phospho-MYPT1 ${ }^{\mathrm{S445}}$ (Figure 2f). Collectively, these data suggest that $\mathrm{Ca}^{2+}$ signalling activates NUAK1 in the absence of LKB1. Interestingly, treatment with the $\mathrm{Ca}^{2+}$ ionophore $\mathrm{A} 23187$ could partially rescue MYPT1 ${ }^{\mathrm{S} 445}$ phosphorylation in the presence of NUAK1 inhibitor but not in the presence of the dual NUAK1/NUAK2 inhibitor, WZ4003 (Supplementary Figure S1A). A23187 also partially rescued MYPT1 $^{\text {S445 }}$ phosphorylation upon suppression of either NUAK1 or NUAK2 but not both (Supplementary Figure S1B), together suggesting that NUAK2 is also activated by calcium signalling in the absence of LKB1.

MYC drives increased PKC activity

Calcium regulates multiple kinases including $\mathrm{Ca}^{2+} /$ Calmodulindependent kinases 1-4; CamKK1 and 2; and conventional isoforms of protein kinase $\mathrm{C}$ ( $\mathrm{CPKC}$ ). Noting our previously described link 

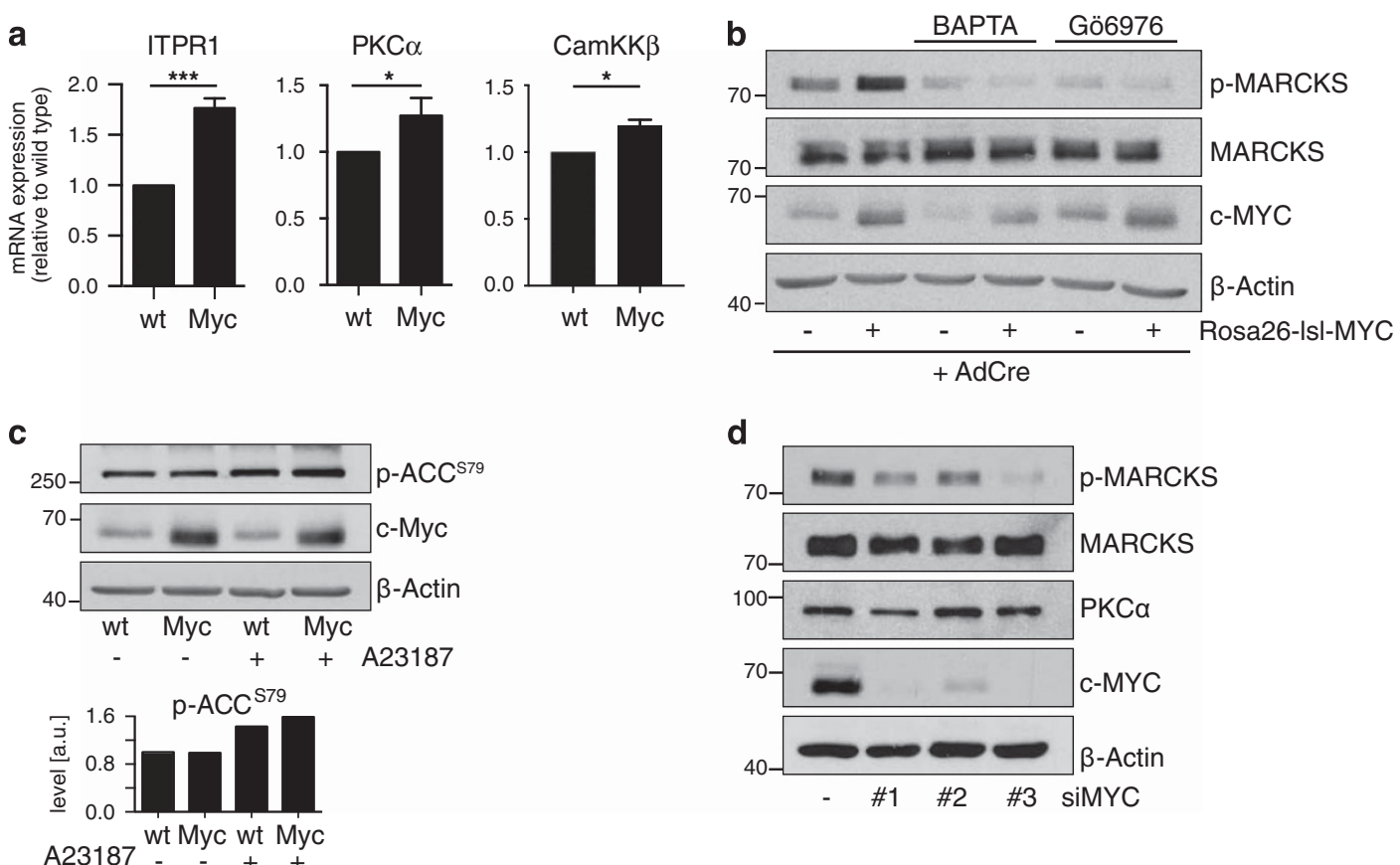

Figure 3. MYC selects for increased calcium signalling. (a) Total RNA isolated from WT or Rosa26-IsI-MYC MEFs harvested $24 \mathrm{~h}$ after infection with Adeno-CRE was analysed by Q-PCR for expression of the indicated transcripts. Mean and s.d. from biological triplicates shown. Statistical significance was determined by two-tailed unpaired T-tests. (b) Immunoblot from Adeno-CRE-infected WT or Rosa26-Isl-MYC MEFs as per (a) probed for expression and phosphorylation of the PKC substrate MARCKS. Where indicated, MEFs were treated with BAPTA (10 $\mu \mathrm{M}$ for $3 \mathrm{~h}$ ) or Gö6076 (1 $\mu \mathrm{m}$ for $3 \mathrm{~h}$ ) prior to lysis. (c) Lysates from WT and MYC-transformed MEFs, treated as indicated with $10 \mu \mathrm{m}$ A23187 (10 min), probed with the indicated antibodies. Densitometry analysis shows normalized levels of $\mathrm{p}$-ACC ${ }^{\mathrm{S79}}$ from three immunoblots. (d) Immunoblot from HeLa cells upon depletion of MYC using three independent siRNAs versus non-targeting control (-), probed for p-MARCKS ${ }^{\mathrm{S159} / 163}$. All images are representative of at least three independent experiments, except (d) where $N=2$.

between NUAK1 and MYC overexpression, we wondered if MYC might drive expression of a calcium-dependent kinase upstream of NUAK1. Oncogenic transformation of mouse embryo fibroblasts (MEFs) with MYC specifically increased expression of PKCa and CamKK $\beta$, along with the inositol tri-phosphate receptor ITPR1, which regulates calcium release from the endoplasmic reticulum (Figure 3a). Notably, MYC was previously shown to bind the promoters of all three genes in diverse cell types, including MEFs. ${ }^{30}$ MYC overexpression strongly enhanced PKC activity, as measured by phosphorylation of the canonical PKC substrate MARCKS, ${ }^{31}$ and modestly but reproducibly enhanced $\mathrm{Ca}^{2+}$-dependent activation of AMPK (Figures $3 \mathrm{~b}$ and $\mathrm{c}$ ). MARCKS phosphorylation was suppressed by BAPTA or by treatment with the PKCa/ $\beta$ inhibitor Gö6976, ${ }^{32}$ suggesting that deregulated MYC specifically increases activity of $\mathrm{Ca}^{2+}$-dependent PKC isoforms (Figure 3b). HeLa cells express high levels of MYC ${ }^{33}$ and depletion of MYC in HeLa cells reduced p-MARCKS levels (Figure $3 d$ ), suggesting that this consequence of MYC overexpression is conserved across species.

\section{NUAK1 is activated by PKCa}

We next asked if targeted suppression of PKC impairs NUAK1 activity. Inhibition of PKCa and $\beta$ isoforms with Gö6976 strongly reduced $\mathrm{p}-\mathrm{MYPT} 1^{\mathrm{S} 445}$ in a dose-dependent manner (Figure 4a). Notably, this effect was transient, as p-MYPT1 ${ }^{\mathrm{S4} 45}$ levels rebounded within $16 \mathrm{~h}$ of Gö6976 treatment, and this was mirrored by a recovery in overall PKC activity (Figure 4b). SiRNA-mediated depletion of PKCa also reduced p-MYPT1 ${ }^{\mathrm{S445}}$ levels to a degree that was similar to NUAK1 inhibition but less than that observed after $1 \mathrm{~h}$ treatment with the highest concentration of Gö6976 tested, which may reflect promiscuity of the PKC inhibitor at this dose (Figure 4c; note that a lower concentration of Gö6976, $0.5 \mu \mathrm{m}$, was used for all subsequent experiments). No effect on $\mathrm{p}-\mathrm{MYPT} 11^{\mathrm{S445}}$ was observed using siRNA targeting PKC $\beta 1$ (not shown).

In light of our data showing that both NUAK1 and NUAK2 contribute to $\mathrm{Ca}^{2+}$ - induced MYPT1 ${ }^{\mathrm{S} 445}$ phosphorylation, we asked if the effects of PKCa depletion were mediated by either NUAK1, NUAK2, or both. The reduction of $\mathrm{p}-\mathrm{MYPT} 1^{\mathrm{S445}}$ achieved upon NUAK1 depletion was minimally influenced by co-depletion of PKCa (compare lane 2 with lane 4), consistent with a role for PKCa upstream of NUAK1. In contrast, suppression of MYPT1 ${ }^{5445}$ phosphorylation by NUAK2 depletion was strongly enhanced by co-depletion of PKCa (compare lanes 5 and 6), suggesting that NUAK2 resides in a distinct pathway (Figure 4d). Interestingly, depletion of PKCa consistently reduced expression of NUAK1 (Figure 4d). This effect was observed using two independent siRNAs targeting PKCa and neither siRNA influenced NUAK1 mRNA levels (Supplementary Figure S2), strongly suggesting that the effect does not reflect off-target activity of the siRNAs used. Proteasome inhibition largely rescued NUAK1 levels upon depletion of $\mathrm{PKCa}$, suggesting that PKCa promotes NUAK1 protein stability (Supplementary Figures S2B and C).

To examine the effects of acute calcium signalling on NUAK1 activation, we requisitioned an affinity-purified phosphopeptide antibody against T211-phosphorylated NUAK1, and overexpressed either wild type or T211A mutant, FLAG-tagged, NUAK1 in HeLa cells. In FLAG immunoprecipitates, the antibody strongly detected a band migrating at the correct size for NUAK1 only in lysates from WT but not from T211A mutant-overexpressing cells. Identical results were obtained using a commercial anti-phospho$\mathrm{AMPKa}^{\mathrm{T} 172}$ antibody that cross-reacts with overexpressed phospho-NUAK1 ${ }^{\text {T21134 }}$ (Supplementary Figure S2). For both antibodies, the intensity of this band increased within 10 min of $\mathrm{Ca}^{2+}$ ionophore treatment and decreased upon acute treatment with PKC inhibitor (Figure $4 \mathrm{e}$ and Supplementary Figure S2). 

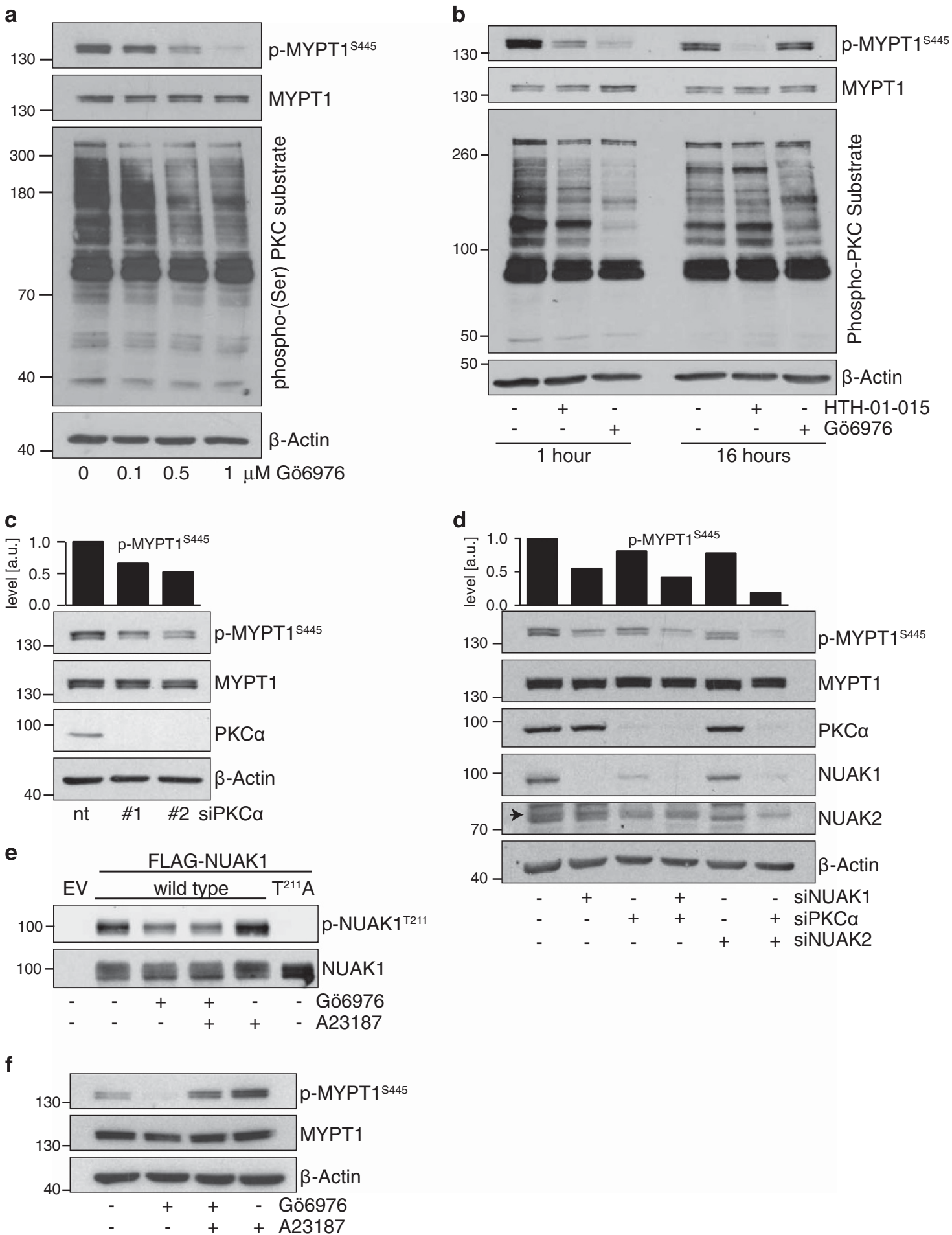

Figure 4. PKC $\alpha$ mediates calcium-dependent NUAK1 activation. (a) Lysates from HeLa cells treated with the indicated concentrations of Gö6976 for $1 \mathrm{~h}$ and probed with the indicated antibodies. (b) Lysates from HeLa cells treated with $1 \mu \mathrm{m}$ Gö6976 or $10 \mu \mathrm{m} \mathrm{HTH-01-015} \mathrm{for} 1$ or $16 \mathrm{~h}$, probed with the indicated antibodies. (c) Lysates from HeLa cells transfected with PKC $\alpha$ siRNA and probed for phospho-S445 and total MYPT1 with densitometry of p-MYPT1 above. nt, non-targeting control siRNA. (d) Lysates form HeLa cells transfected with siRNA targeting PKC $\alpha$ and/or NUAK2 or NUAK1, probed with the indicated antibodies. Arrowhead indicates the correct band for NUAK2. (e) Anti-FLAG immunoprecipitates from HeLa cells transfected with FLAG-tagged WT or T211A mutant NUAK1, treated with $0.5 \mu \mathrm{m}$ Gö6976 and/or $3 \mu \mathrm{m}$ A23187, and probed with anti-phospho-NUAK1 ${ }^{\mathrm{T} 211}$ antibody. (f) Lysates from HeLa cells pre-treated with $0.5 \mu \mathrm{M}$ Gö6976 for $1 \mathrm{~h}$ prior to stimulation with $3 \mu \mathrm{M}$ A23187, as per (e) and probed for phosphor-MYPT1 ${ }^{\text {s445 }}$. All images are representative of at least three independent experiments, except (e) where $N=2$. 
Examination of p-MYPT1 ${ }^{\mathrm{S} 445}$ under the same conditions showed similar responses to $\mathrm{Ca}^{2+}$ ionophore and PKC inhibitor treatment with one important difference: whereas $\mathrm{Ca}^{2+}$ ionophore could partially rescue the effect of Gö6976 on MYPT1 ${ }^{\text {S445 }}$ phosphorylation (Figure 4f), no such rescue was evident in p-NUAK1 ${ }^{\text {T211 }}$ levels. Taken with the data above, these data suggest that $\mathrm{Ca}^{2+}$ signalling regulates NUAK1 in HeLa cells via activation of PKCa, while MYPT $1^{\mathrm{S} 445}$ phosphorylation is regulated both via NUAK1 and via a distinct pathway involving $\mathrm{Ca}^{2+}$-dependent, Gö6976-refractory, activation of NUAK2.

The PKCa-NUAK1 pathway supports viability of MYC-overexpressing cells

We previously showed that MYC-overexpressing cells require NUAK1 to sustain viability. ${ }^{21}$ HeLa cells express high levels of MYC a
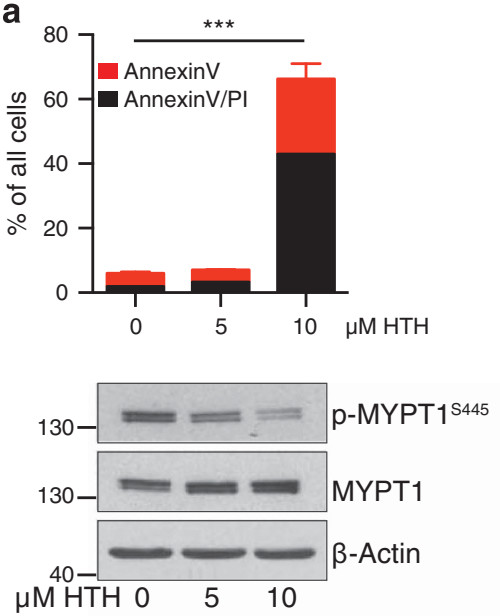

d
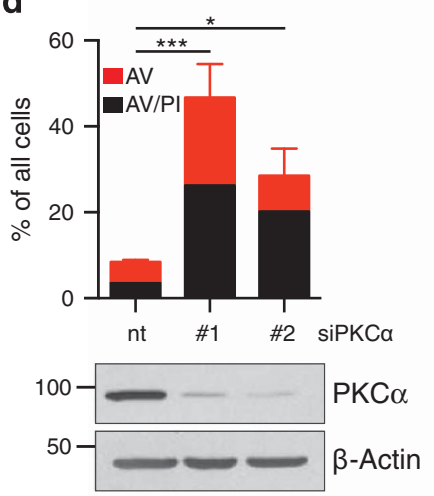

f
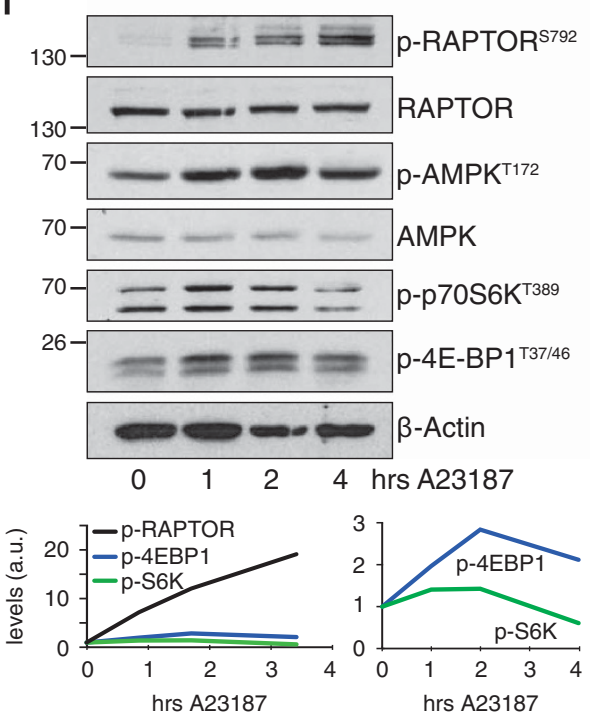

Figure 5. For caption see page 988. b

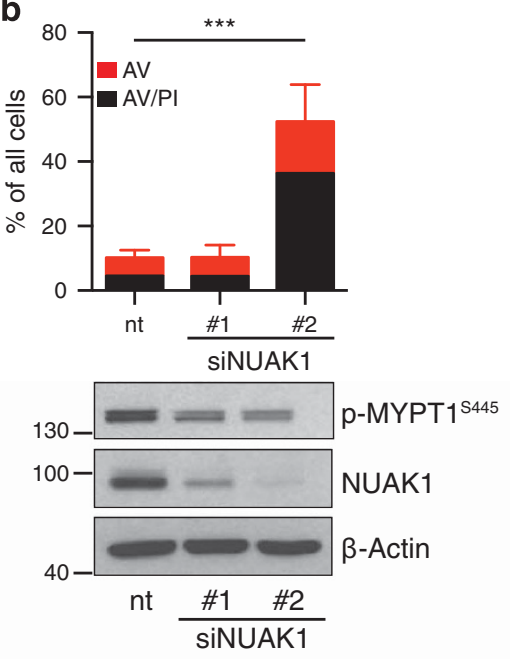

e

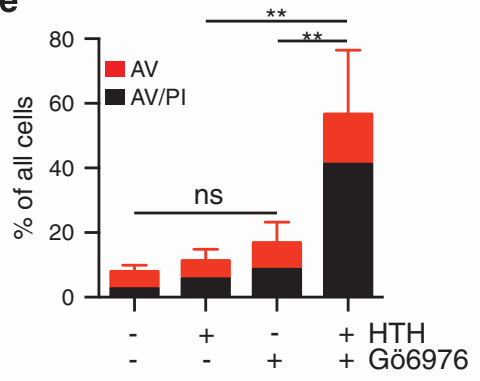

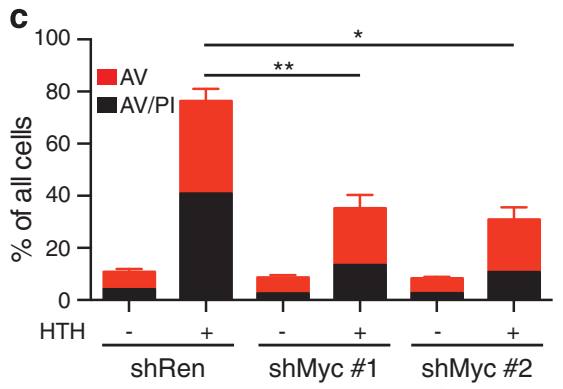
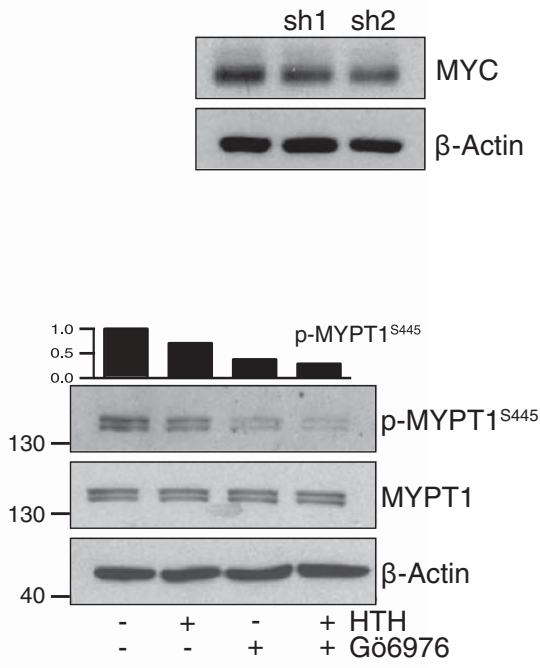

g

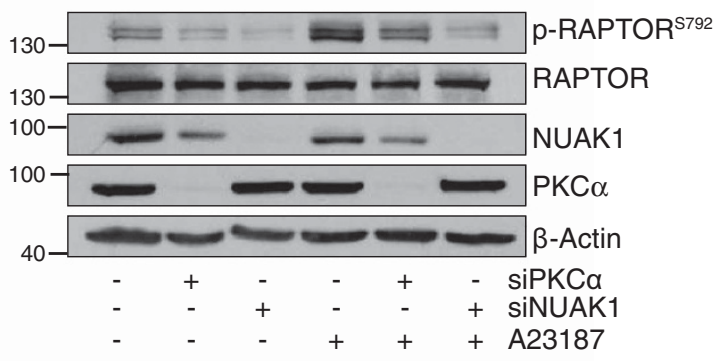

h

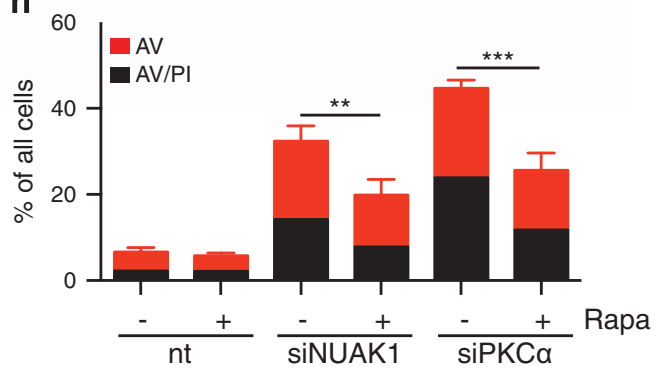


and prolonged treatment ( 2 days) with $10 \mu \mathrm{M} \mathrm{HTH-01-015} \mathrm{resulted}$ in pronounced HeLa cell apoptosis (Figure $5 \mathrm{a}$ ). Partial inhibition of NUAK1 with $5 \mu \mathrm{M}$ HTH-01-015 was surprisingly well tolerated, suggesting that a threshold level of NUAK1 activity is sufficient to prevent cell death. Similar results were obtained using siRNAmediated NUAK1 depletion, in that death was only induced upon very strong suppression of NUAK1 expression (Figure 5b). Death induced by $10 \mu \mathrm{m}$ HTH-01-015 was significantly attenuated by reducing MYC levels with either of two MYC-targeting shRNAs (Figure 5c), consistent with our previous demonstration of MYC 'dose-dependence' for the synthetic lethal interaction with NUAK1. ${ }^{21}$ Consistent with a role for PKCa upstream of NUAK1, depletion of PKCa with either of two siRNAs also drove pronounced HeLa cell apoptosis (Figure $5 \mathrm{~d}$ ), while treatment of HeLa cells with Gö6976 significantly enhanced killing by a sublethal dose of NUAK1 inhibitor (Figure 5e). Note that Gö6976 treatment alone did not kill HeLa cells, likely owing to the transient nature of PKC inhibition by this compound (Figure 4b).

We asked if death induced upon loss of PKCa mechanistically mirrored that induced by loss of NUAK1. Under conditions of energetic stress, cancer cells activate a metabolic checkpoint in order to limit mTORC1-driven macromolecular synthesis, via phosphorylation of RAPTOR-Ser ${ }^{792}$ by AMPK. ${ }^{35}$ Failure to engage this checkpoint results in death of stressed cells $s^{24,36}$ and our previous work showed that NUAK1 is required for efficient checkpoint activation. ${ }^{21}$ Dynamic analysis of this checkpoint in HeLa cells revealed a complex response to $\mathrm{Ca}^{2+}$ ionophore, with p-RAPTOR $^{5792}$ increasing steadily over time whereas phosphoS6K $\mathrm{K}^{\mathrm{T} 389}$ and phospho-4EBP1 ${ }^{\mathrm{T37} / 46}$ levels, downstream of mTORC1, rose initially before declining (Figure 5f), consistent with $\mathrm{Ca}^{2+}$ simultaneously activating the mTORC1 pathway as well as the inhibitory AMPK-Raptor pathway. ${ }^{37}$ Importantly, depletion of either PKCa or NUAK1 reduced both basal and $\mathrm{Ca}^{2+}$-activated phosphorylation of RAPTOR-Ser ${ }^{792}$, suggesting that failure to efficiently engage the metabolic checkpoint may contribute to death in both instances (Figure $5 \mathrm{~g}$ ). Consistent with this hypothesis, treatment of HeLa cells with the mTORC1 inhibitor Rapamycin significantly rescued cells from death induced by depletion of either NUAK1 or PKCa, and the degree of rescue was similar in both instances (Figure 5h). Although these data do suggest that other downstream pathways likely contribute to cell death, they strongly support the core observation that NUAK1 and $\mathrm{PKCa}$ act in a similar manner to support cell viability.

NUAK1 regulates RAPTOR via both AMPK-dependent and independent mechanisms

Confirming the requirement for NUAK1 to restrain mTORC1 activity, 535 -Methionine labelling showed increased protein translation in NUAK1-depleted HeLa and U2OS cells (Figure 6a), as shown previously. ${ }^{21}$ We therefore examined RAPTOR regulation by NUAK1 in greater detail. Activation of AMPK by $\mathrm{Ca}^{2+}$ ionophore (A23187), phenformin or salicylate in U2OS cells all lead to increased RAPTOR ${ }^{\mathrm{S} 792}$ phosphorylation. In contrast with the selective requirement for NUAK1 during AMPK regulation of ACC, RAPTOR ${ }^{5792}$ phosphorylation was reduced by NUAK1 inhibition under all conditions examined (Figure 6b). Depletion of NUAK1 also significantly reduced both basal and AMPKactivated RAPTOR ${ }^{\mathrm{ST} 92}$ phosphorylation, confirming the specificity of this effect (Figure $6 \mathrm{c}$ ). Inhibition of NUAK1 reduced AMPKdependent RAPTOR $^{\mathrm{S} 792}$ phosphorylation in immortalized Prkaa $^{F L / F L}$;Prkaa2 ${ }^{F L / F L}$ double floxed MEFs. Strikingly, phosphoRAPTOR $^{5792}$ was still detectable in the same MEFs after CRE recombinase-mediated deletion of AMPKa1 and a2, albeit at reduced levels, and NUAK1 inhibition further reduced detection, indicating that NUAK1 can regulate RAPTOR in the absence of functional AMPK (Figure 6d). Accordingly, deletion of NUAK1 in Nuak $1^{\mathrm{FL} / \mathrm{FL}}$ MEFs also reduced both basal and AMPK-activated RAPTOR $^{\mathrm{S} 792}$ phosphorylation (Figure 6e). Together these data show that efficient restraint of mTORC1 via inhibitory phosphorylation of RAPTOR requires both NUAK1 and AMPK.

\section{DISCUSSION}

Suppression of NUAK1 is synthetic lethal with MYC overexpression, suggesting that NUAK1 may present an attractive target for treatment of MYC-driven cancers. ${ }^{21,38} \mathrm{~A}$ thorough understanding of the signal transduction context of NUAK1 will be crucial to determine if such a strategy is feasible in human subjects. Here we show that NUAK1 is active in HeLa cells despite the absence of LKB1. We show modulation of NUAK1 activity by calcium perturbation, and present evidence that PKCa participates in NUAK1 activation in response to $\mathrm{Ca}^{2+}$ signalling. Importantly, $\mathrm{Ca}^{2+}$-dependent activation of the AMPK-mTORC1 metabolic checkpoint requires both $\mathrm{PKCa}$ and NUAK1, and depletion of either drives pronounced apoptosis, suggesting a positive role for this pathway in tumour maintenance. Our specific findings are summarized in Figure 7.

It is widely thought that the tumour suppressive function of LKB1 is mediated by one or more of the AMPK-family kinases. ${ }^{27,39}$ Loss of LKB1 would thus be predicted to result in loss of ARK activity, downstream. Accordingly, deletion of Stk11, encoding Lkb1, in wild-type MEFs was shown to suppress activity of AMPK and all related ARKs, as measured in cell-free kinase assays using a peptide substrate optimized for AMPK. ${ }^{1}$ However, several of the ARKs, including Nuak1, showed only weak activity towards the peptide used, suggesting it was a suboptimal substrate for these kinases. Indeed, subtle differences in peptide substrate sequences have revealed distinct preferential phosphorylation patterns of AMPK and MARK kinases. ${ }^{40}$ Thus, in vitro kinase assays with a onesize-fits-all peptide substrate likely fail to accurately reflect

Figure 5. The PKCa-NUAK1 pathway supports viability of MYC-overexpressing cells. (a) Apoptosis induced in HeLa cells by the indicated doses of HTH-01-015, measured by FACS analysis of cells stained with Annexin V and propidium iodide (AV/PI) $48 \mathrm{~h}$ post-treatment: Red bars denote AV single-positive cells while black bars denote AV/PI double-positive cells (for a-e, $\mathbf{h}$ ). Mean and s.d. of three independent experiments shown (a, b, d, e, h). Statistical significance was determined by one-way ANOVA, Tukey's multiple comparison test (a-e). The immunoblot shows suppression of MYPT1 phosphorylation after $1 \mathrm{~h}$ treatment. (b) Apoptosis in HeLa cells induced by NUAK1 siRNA, measured 3 days post-transfection. Immunoblot shows NUAK1 and p-MYPT1 levels at $24 \mathrm{~h}$. nt, non-targeting control siRNA. (c) Apoptosis induced by $10 \mu \mathrm{m}$ HTH-01-015 in HeLa cells transfected with MYC shRNA where indicated. Mean and s.d. of technical triplicates from a representative (median) experiment shown due to wide inter-experimental variation in efficiency of MYC depletion. $N=5$. (d) Apoptosis induced in HeLa cells by PKC $\alpha$ siRNA, measured 3 days post-transfection. Immunoblot shows PKC $\alpha$ levels after $24 \mathrm{~h}$. nt, non-targeting control siRNA. (e) Apoptosis induced in HeLa cells after treatment with $5 \mu \mathrm{M}$ HTH-01-015 $\pm 0.5 \mu \mathrm{m}$ Gö6976 for $48 \mathrm{~h}$. Immunoblot shows p-MYPT1 ${ }^{\text {s445 }}$ levels after $1 \mathrm{~h}$ drug treatment. (f) Dynamic response of the AMPK-mTORC1 pathway to calcium mobilization. HeLa cells were harvested at 0, 1, 2 and $4 \mathrm{~h}$ post-treatment with $3 \mu \mathrm{M}$ A23187 and probed with the indicated antibodies. The graphs show densitometric measurements of p-RAPTOR ${ }^{\text {S792 }}$, p-S6K ${ }^{\text {T389 }}$ and p-4EBP $1^{\text {T37/46 }}$ from the blots shown, normalized to Actin. $N=2$. (g) Lysates from HeLa cells transfected with NUAK1, PKC $\alpha$ or non-targeting ( - ) siRNA for $24 \mathrm{~h}$ and stimulated with $3 \mu \mathrm{m} \mathrm{A23187} \mathrm{for} 10 \mathrm{~min}$, as indicated, probed with the indicated antibodies. $N=2$. (h) Apoptosis induced by depletion of either NUAK1 or PKC $\alpha$ in cells treated for $48 \mathrm{~h}$ with $100 \mathrm{~nm}$ Rapamycin (Rapa) or DMSO vehicle control (-), measured by AV/PI FACS. Two-way ANOVA, Sidak's multiple comparison test. 
a

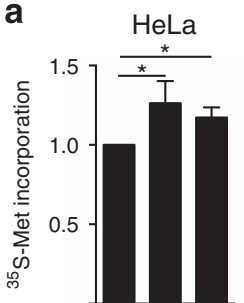

sint $0^{\circ} t^{\circ}$

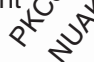

b

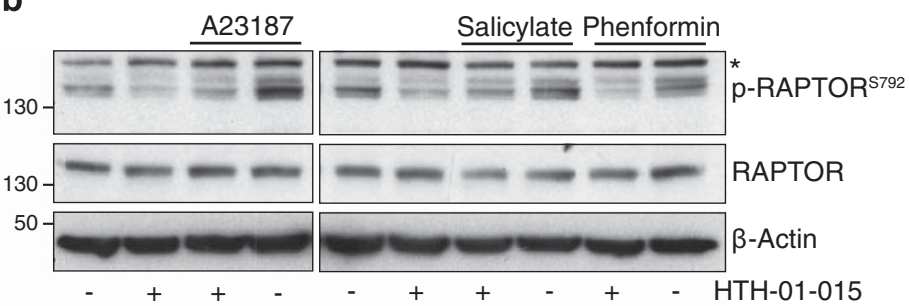

c

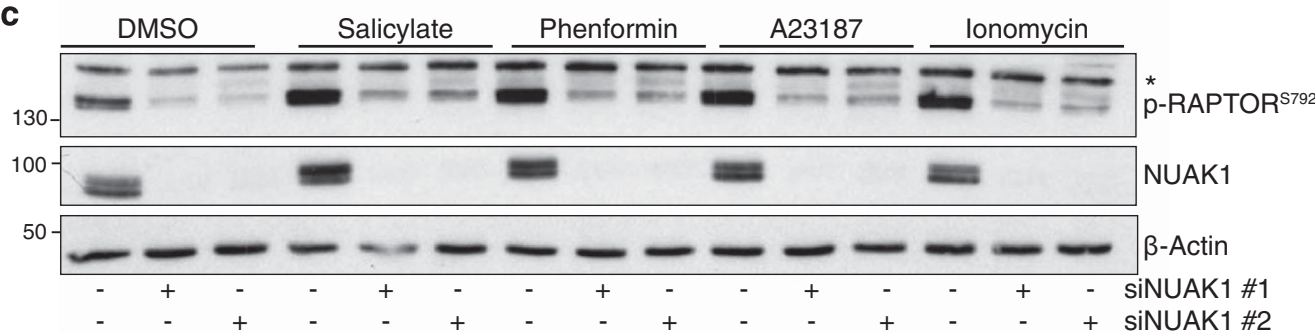

d

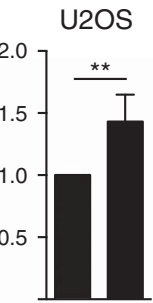

si nt $\hat{t}$

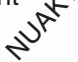

+ siNUAK1 \#2

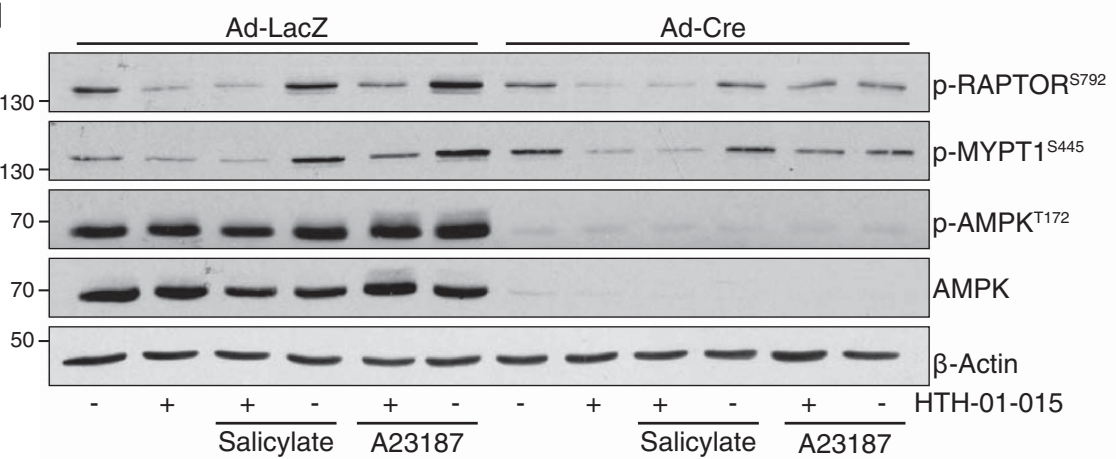

e

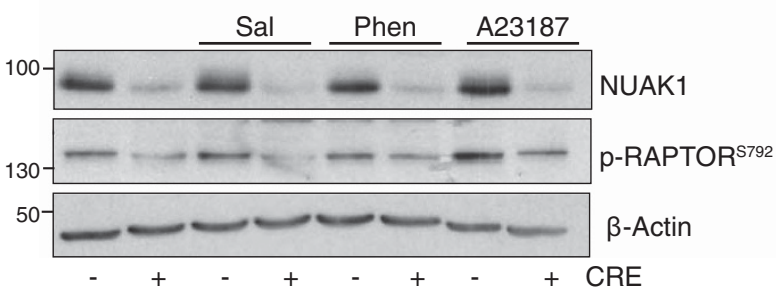

Figure 6. NUAK1 regulates RAPTOR via AMPK-dependent and independent mechanisms. (a) Measurement of protein synthesis (methionine incorporation) in HeLa (left panel) and U2OS (right panel) cells transfected with non-targeting (-), NUAK1 and PKC $\alpha$ siRNA. Mean and s.d. from three independent experiments shown. Statistical significance was determined by one-tailed unpaired T-test. (b) Lysates from U2OS cells pre-treated with $10 \mu \mathrm{M} \mathrm{HTH}-01-015$ for $1 \mathrm{~h}$, where indicated, prior to treatment with $6 \mu \mathrm{m} \mathrm{A23187}(10 \mathrm{~min}), 10 \mathrm{~mm}$ salicylate $(1 \mathrm{~h}), 10 \mathrm{~mm}$ phenformin $(1 \mathrm{~h})$ or DMSO vehicle and blotted for phospho-S792 and total RAPTOR. $N=3$. The asterisk denotes a nonspecific band in the p-RAPTOR panel $(\mathbf{b}, \mathbf{c})$. (c) Lysates from U2OS cells transfected where indicated with siRNA targeting NUAK1 and treated with 10 mM salicylate $(1 \mathrm{~h}), 10 \mathrm{~mm}$ phenformin $(1 \mathrm{~h}), 6 \mu \mathrm{m}$ A23187 $(10 \mathrm{~min}), 3 \mu \mathrm{m}$ lonomycin $(10 \mathrm{~min})$ or DMSO vehicle, blotted for p-RAPTOR ${ }^{\mathrm{S} 792}$. N=3. (d) Lysates from immortalized Prkaa ${ }^{F L / F L}$; Prkaa2 ${ }^{F L / F L}$ double floxed MEFs, infected overnight with Adeno-LacZ or Adeno-CRE and treated as per (c) with AMPK activators in the presence or absence of $10 \mu \mathrm{M}$ HTH-01-015, blotted with the indicated antibodies. $N=2$. (e) Lysates from primary Nuak $1^{F L / F L}$ MEFs stably expressing Cre-ER were treated overnight with $100 \mathrm{~nm} 4-\mathrm{OH}-\mathrm{Tamoxifen}(+)$ or vehicle control ( - ) prior to stimulation as per (d, e) with AMPK activators, then immunoblotted for -Raptor $^{5792} . N=2$.

physiological ARK activity in cells. Additionally, several independent groups have definitively shown that AMPK is directly phosphorylated by CamKK2, reflecting an alternative pathway to AMPK activation. ${ }^{25,26,41,42}$ Activation of AMPK by CamKK2 is particularly important in prostate cancer and in the physiological regulation of skeletal muscle and vascular endothelial cell function. ${ }^{43-45}$ Interestingly, the ARK SIK2 was recently shown to be activated by an as-yet unidentified $\mathrm{Ca}^{2+}$-dependent kinase in Ovarian cancer cells. ${ }^{46}$ Our demonstration that NUAK1 and NUAK2 are similarly regulated by $\mathrm{Ca}^{2+}$-dependent signalling thus fits an emerging pattern of calcium regulating multiple ARKs, either alongside or in the absence of LKB1. This regulation may have particular relevance in LKB1-deficient disease settings.

Our data speak to the complexity of signal transduction through AMPK, NUAK1 and the related ARKs. Indeed, AMPK is often discussed as if it were a single entity. Rather, up to 12 different permutations of trimeric AMPK complexes can assemble from the $2 a, 2 \beta$ and $3 \gamma$-encoded subunits, not accounting for splice variants. ${ }^{22}$ It is likely that the different AMPK complexes may respond differentially to distinct upstream stimuli, and indeed in 


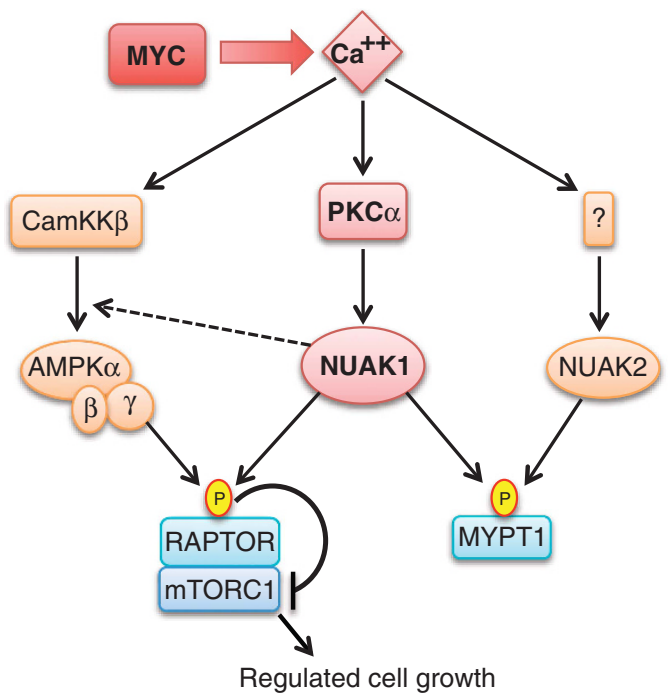

Figure 7. Diagram of calcium regulation of NUAK1, NUAK2 and AMPK.

terms of their activity towards specific downstream substrates. Our demonstration of a specific requirement for NUAK1 in $\mathrm{Ca}^{2+}$ -dependent AMPK activity towards ACC, and a more general requirement for NUAK1 in AMPK activity towards RAPTOR, point towards a highly contextual requirement for NUAK1 and may indicate that NUAK1 modulates the activity of a specific subset of AMPK complexes. On top of this, the 11 related ARKs can exhibit both overlapping and private substrate specificities. This is reflected by our demonstration of an AMPK-independent role for NUAK1 in RAPTOR regulation, and by phosphorylation of MYPT1 by NUAK1, NUAK2 and potentially by additional ARKs. Consistent with this, we also find $\mathrm{Ca}^{2+}$-dependent phosphorylation of the canonical AMPK substrate ACC even after complete suppression of CamKK $\beta$-dependent AMPK activity in HeLa cells. Clearly, considerably more work will be needed to disentangle these complex signalling networks.

Whereas calcium has long been recognized to drive MYC expression ${ }^{47}$ and more recently to regulate MYC function, ${ }^{48,49}$ the reciprocal regulation of calcium signalling by MYC has not garnered much attention. MYC was shown to increase calcium signalling during B-cell differentiation by suppressing expression of the calcium exporter PMCA. ${ }^{50}$ ChIP-SEQ analysis has revealed MYC binding to the promoters of ITPR1-3, PRKCA and CamKK2 in diverse cell types, ${ }^{30}$ consistent with our observation that MYC promotes expression of these genes. The pronounced increase in phosphorylation of the PKC substrate MARCKS compared with the much more modest effect of MYC overexpression on PKCa levels suggests that regulation of this pathway by MYC is only partially explained by the observed transcriptional effects. Nevertheless, our data do suggest that MYC actively selects for increased cellular sensitivity to calcium, and does so in part to promote NUAK1 activity, maintain metabolic homoeostasis and thereby sustain cell viability. The relative contribution of calcium signalling to NUAK1 activation likely depends on several factors including the strength of calcium signalling, whether LKB1 is present or absent and, if present, the relative levels of PKCa and LKB1 upstream.

MYC is a paradigm driver of apoptosis when expressed at high levels ${ }^{51,52}$ whereas conventional PKC isoforms inhibit apoptosis in many cell types. ${ }^{53}$ Suppression of PKCa or $\beta$ induces apoptosis, ${ }^{54-56}$ whereas overexpression has been shown to suppress death induced by MYC or withdrawal of IL3. ${ }^{57,58}$ Both $\mathrm{PKCa}$ and $\beta$ isoforms have been shown to promote $\mathrm{Ser}^{473}$ phosphorylation of AKT, ${ }^{59,60}$ which inhibits canonical MYCinduced apoptosis, primarily via suppression of pro-apoptotic
BH3 protein expression/function. ${ }^{61-63}$ Importantly, we showed previously that MYC-overexpressing cells continue to require NUAK1 even when active AKT is overexpressed, ${ }^{21}$ pointing to a role for NUAK1 in protecting tumour cells from non-apoptotic cell death and suggesting that calcium and PKCa may govern multiple pathways that promote tumour cell survival. Targeted suppression of these pathways may thus have therapeutic benefit in multiple cancers where MYC is deregulated. ${ }^{64}$

\section{MATERIALS AND METHODS}

Cell culture

The identity of all cell lines was verified using an in-house cell line validation service. HeLa and U2OS cells were maintained in Dulbecco's modified Eagles's medium containing $4.5 \mathrm{~g} / \mathrm{l}$ glucose, $1 \%$ glutamine, $100 \mathrm{U} / \mathrm{ml}$ of streptomycin, $100 \mathrm{U} / \mathrm{ml}$ of penicillin, $10 \%$ fetal bovine serum and incubated at $37^{\circ} \mathrm{C}$ in $5 \% \mathrm{CO}_{2}$. Primary MEFs were isolated from mouse embryos (wild type; Rosa26-IsIMyc; Nuak1 $1^{\mathrm{FL} / \mathrm{FL}}$ ) at E13.5 days and cultured as above except for incubation in $3 \%$ oxygen. All cell lines were routinely tested for mycoplasma contamination and were validated by STR profiling using an approved in-house validation service (CRUK-BICR). Wild type, Rosa26-IsI-MYC MEFs were infected with 300 multiplicity of infection of Adeno-Cre replication-incompetent virus (University of lowa) to induce MYC expression. Nuak $1^{\mathrm{FL} / \mathrm{FL}}$ MEFs were infected with retrovirus expressing tamoxifen-inducible Cre-ER and selected on puromycin. SV40 T antigen-immortalized Prkaa1 ${ }^{F L / F L}$; Prkaa2 ${ }^{F / F L}$ double floxed MEFs were generously provided by Russell Jones, McGill University. For transient transfection, HeLa cells were plated on $10 \mathrm{~cm}$ diameter dishes and transfected with $3 \mu \mathrm{g}$ of DNA (FLAG-NUAK1wt, FLAG-NUAK1T211A or empty vector) using Lipofectamine 3000 (Thermo Fisher, Waltham, MA, USA) and lysed $48 \mathrm{~h}$ post-transfection. For protein translation measurements, cells were cultured for with $30 \mu \mathrm{Ci} / \mathrm{ml}{ }^{35} \mathrm{~S}$ Methionine label (EasyTag from Perkin Elmer, Beaconsfield, UK) for $30 \mathrm{~min}$ and total protein was precipitated using a final concentration of $12.5 \%$ trichloroacetic acid. Scintillation (Ecoscint, Thermo Fisher) was counted for $2 \mathrm{~min}$.

Chemicals and antibodies

Phenformin, Sto-609, Rapamycin, phosphatase inhibitor cocktails (P0044 and P5726), protease inhibitor cocktail (P8340) and MG132 were purchased from Sigma-Aldrich (Irvine, UK); HTH-01-015 from Cambridge Bioscience (Cambridge, UK); A23187, lonomycin and A769662 from Abcam (Cambridge, UK); WZ4003, Gö6976 and BAPTA-AM were purchased from Tocris (Bristol, UK). Antibodies recognizing ACC phospho-Ser79(\#3661), total ACC (\#3676), Raptor phospho-Ser792(\#2083), total Raptor (\#3661), AMPK phosphoT172(\#2535), total AMPK (\#2532), total MYPT1 (\#8574), PKCa (\#2056), NUAK1 (\#4458), phospho-(Ser) PKC substrate (\#2261), MARCKS phospho-Ser159/163 (\#11992) were purchased from Cell Signalling Technologies (Danvers, MA, USA); anti-FLAG (\#F1804), anti- $\beta$-Actin (\#A5441) were from Sigma-Aldrich; anti-MYPT1 phospho-Ser445(\#S508C) and anti-NUAK2 (\#S225B) were from the MRC PPU, Dundee, UK; anti-MARCKS (\#ab72459) anti-Histone H2B (\#ab1790), anti-Vinculin (\#ab129002) and anti-c-Myc (\#ab32072) were purchased from Abcam. The phospho-T211 NUAK1 antibody was generated by Eurogentec (Liege, Belgium) against the phosphopeptide KFLQT ${ }^{\mathrm{PO}} \mathrm{FCGSPLY}$. The antibody was affinity purified from reactive serum using the same phosphorpeptide after counter-selection with non-phosphorylated peptide. In addition to the results shown, the antibody was further validated by loss of signal upon siRNA-mediated depletion of NUAK1. Secondary antibodies coupled to horseradish peroxidase anti-mouse and anti-rabbit were purchased from GE Healthcare (\#NA931 and \#NA934; Chicago, IL, USA), and anti-sheep was from Pierce (\#31480; Thermo Fisher). 
RNA interference

HeLa cells were passaged $12 \mathrm{~h}$ before transfection and transfected at 70\% confluency using Lipofectamine RNAiMAX (Thermo Fisher) with the following siRNA from Qiagen (Manchester, UK): nontargeting control (1022076), NUAK1\#1 (SI00108388), NUAK1\#2 (SI00108388), PKCa\#1 (SI00605934), PKCa\#2 (SI00605927), NUAK2 (SI02660224), MYC\#1 (SI00300902), MYC\#2 (SI02662611), MYC\#3 (SI03101847). shRNA against human MYC and a non-targeting control (Renilla) were designed by and purchased from Mirimus Inc. (Woodbury, NY, USA): ShMYC1702-CGCCTCCCTCCACTCGGAAGGA; shMYC1891-CTGAGTCTTGAGACTGAAAGAT. HeLa cells were transfected with $3 \mu \mathrm{g}$ of shRNA-encoding plasmid using Lipofectamine 3000. After transfection, cells were treated and analysed as for figure legends.

\section{Quantitative real-time PCR}

RNA was isolated by Trizol and was reversed transcribed using QuantiTect Reverse Transcription Kit (Qiagen), according to the manufacturer's instructions. Real-time quantification was performed using SYBR Green Fast Mix (VWR, Lutterworth, UK) with C1000 thermal cycler (Bio-Rad, Watford, UK). Primers for NUAK1 (forward, 5'-ccgctcactgatgtaatcgt; reverse, 5'-gtcatctctcaaccatcctcat), ACTIN (forward, 5'-ccaaccgcgagaagatga; reverse, 5'-ccaga ggcgtacagggatag) ITPR1 (forward, 5'-GAAGGCATCTTTGGAGG AAGT-3'; reverse, 5'-ACCCTGAGGA-AGGTTCTG-3'), PKCa (forward, 5'-CAAGGGATGAAATGTGACACC-3'; reverse, 5'-CCTCTTCT-CTGTG TGATCCATTC-3'), CaMKK $\beta$ (forward, 5'-GGAGGTCGAGAACTC AGTCAA; reverse, 5'-CATGGTCTTCACCAGGATCA) and $\beta 2 \mathrm{~m}$ (forward, 5'-ACCTCCATGATGCTGCTTAC-3'; reverse, 5'-GGACTGGTC TाTCTATCTCTTGTAC-3') were obtained from IDT (Leuven, Belgium).

Immunoprecipitation and immunoblotting

FLAG-NUAK1 wild type, mutant (T211A) or empty vector transiently overexpressed HeLa cells were rinsed with ice-cold phosphate-buffered saline and then lysed in Lysis Buffer containing $50 \mathrm{~mm}$ Tris- $\mathrm{HCl}(\mathrm{pH} 7.5), 1 \% \mathrm{NP}-40,0.27 \mathrm{M}$ sucrose and phosphatase/protease inhibitors. Cell lysates $(1 \mathrm{mg})$ were incubated overnight at $4{ }^{\circ} \mathrm{C}$ with anti-FLAG M2 Affinity gel (Sigma, Irvine, UK; A2220). Immunoprecipitated were washed twice with Lysis Buffer containing $0.15 \mathrm{M} \mathrm{NaCl}$, twice with $50 \mathrm{~mm}$ Tris- $\mathrm{HCl}(\mathrm{pH}$ 7.5) plus phosphatase inhibitors and resuspended in sodium dodecyl sulphate sample buffer. For whole-cell extracts, cells were rinsed with ice-cold phosphate-buffered saline and then lysed in situ with lysis buffer containing $150 \mathrm{~mm} \mathrm{NaCl}, 50 \mathrm{~mm}$ Tris $(\mathrm{pH}$ 7.5), $1 \%$ NP-40, $0.5 \%$ sodium deoxycholic acid, $1 \%$ sodium dodecyl sulphate plus protease and phosphatase inhibitor cocktails. Lysates were then sonicated to reduce viscosity and diluted in sodium dodecyl sulphate sample buffer. Immunoprecipitated and whole-cell extracts were resolved by sodium dodecyl sulphatepolyacrylamide gel electrophoresis, transferred to nitrocellulose membranes for subsequent incubation with primary antibodies overnight at $4{ }^{\circ} \mathrm{C}$. Densitometry analysis of individual immunoblots was performed using ImageJ (NIH, Bethesda, MD, USA).

\section{Cell death analysis}

HeLa cells were treated or transfected as for figure legends and on the day of the analysis the supernatant was collected, cells were rinsed in phosphate-buffered saline and harvested by trypsinization. Cells were then centrifuged at $300 \mathrm{~g}$ for $5 \mathrm{~min}$ at $4{ }^{\circ} \mathrm{C}$ and pellet incubated in $200 \mu$ l Annexin V binding buffer (10 mm HEPES pH 7.4, $140 \mathrm{~mm} \mathrm{NaCl}, 2.5 \mathrm{~mm} \mathrm{CaCl}$ ) containing APC-Annexin V (Biolegend, San Diego, CA, USA) for $10 \mathrm{~min}$ at room temperature. Propidium iodide was added prior to analysis by FACSCalibur (BD Biosciences, Wokingham, UK) flow cytometry.

\section{Statistical analysis}

Raw data were uploaded into Prism (Graphpad, La Jolla, CA, USA) or Excel (Microsoft, Reading, UK) spreadsheets for generation of graphs. All experiments were performed on at least three occasions, except where noted, and mean and s.d. values from biological replicates are presented. Statistical significance was determined by $T$-test and one-way or two-way ANOVA as per figure legends. ${ }^{*}$ denotes $P<0.05 ;{ }^{* *}<0.01 ;{ }^{* *}<0.001$.

\section{CONFLICT OF INTEREST}

The authors declare no conflict of interest.

\section{ACKNOWLEDGEMENTS}

We acknowledge valuable input from the entire Murphy laboratory and numerous colleagues at the University of Glasgow Institute of Cancer Sciences and CRUK Beatson Institute. Nuak1 inhibitors were generously provided by Nathanael Gray prior to commercial availability. TM was supported by grant APHD13-5 from the British Lung Foundation. Additional support was provided by Wellcome trust grant 105614/ Z/14/Z; the European Commission Marie Curie actions CIG 618448 'SERPLUC' to DJM and institutional support provided by the University of Glasgow \& CRUK Beatson Institute to DJM.

\section{AUTHOR CONTRIBUTIONS}

All experiments were performed by TM with assistance from JTM, AH and JK. Data analysis were performed by TM, JTM, AH, JK and DJM. Figures were prepared by TM and the manuscript was written by DJM with assistance from TM, JTM and AH. All authors read and approved the submission.

\section{REFERENCES}

1 Lizcano JM, Goransson O, Toth R, Deak M, Morrice NA, Boudeau J et al. LKB1 is a master kinase that activates 13 kinases of the AMPK subfamily, including MARK/ PAR-1. EMBO J 2004; 23: 833-843.

2 Zagorska A, Deak M, Campbell DG, Banerjee S, Hirano M, Aizawa S et al. New roles for the LKB1-NUAK pathway in controlling myosin phosphatase complexes and cell adhesion. Sci Signal 2010; 3: ra25.

3 Hirano $M$, Kiyonari $H$, Inoue A, Furushima K, Murata $T$, Suda $Y$ et al. A new serine/ threonine protein kinase, Omphk1, essential to ventral body wall formation. Dev Dyn 2006; 235: 2229-2237.

4 Ohmura T, Shioi G, Hirano M, Aizawa S. Neural tube defects by NUAK1 and NUAK2 double mutation. Dev Dyn 2012; 241: 1350-1364.

5 Courchet J, Lewis Jr TL, Lee S, Courchet V, Liou DY, Aizawa S et al. Terminal axon branching is regulated by the LKB1-NUAK1 kinase pathway via presynaptic mitochondrial capture. Cell 2013; 153: 1510-1525.

6 Inazuka F, Sugiyama N, Tomita M, Abe T, Shioi G, Esumi H. Muscle-specific knockout of NUAK family SNF1-like kinase 1 (NUAK1) prevents high fat diet-induced glucose intolerance. J Biol Chem 2012; 287: 16379-16389.

7 Humbert N, Navaratnam N, Augert A, Da Costa M, Martien S, Wang J et al. Regulation of ploidy and senescence by the AMPK-related kinase NUAK1. EMBO J 2010; 29: 376-386.

8 Lasagna-Reeves CA, de Haro M, Hao S, Park J, Rousseaux MW, Al-Ramahi I et al. Reduction of Nuak1 decreases Tau and reverses phenotypes in a tauopathy mouse model. Neuron 2016; 92: 407-418.

9 Kusakai G, Suzuki A, Ogura T, Miyamoto S, Ochiai A, Kaminishi M et al. ARK5 expression in colorectal cancer and its implications for tumor progression. Am J Pathol 2004; 164: 987-995.

10 Riester M, Wei W, Waldron L, Culhane AC, Trippa L, Oliva E et al. Risk prediction for late-stage ovarian cancer by meta-analysis of 1525 patient samples. J Natl Cancer Inst 2014; 106. https://doi.org/10.1093/jnci/dju048.

11 Zhang HY, Li JH, Li G, Wang SR. Activation of ARK5/miR-1181/HOXA10 axis promotes epithelial-mesenchymal transition in ovarian cancer. Oncol Rep 2015; 34: 1193-1202.

12 Phippen NT, Bateman NW, Wang G, Conrads KA, Ao W, Teng PN et al. NUAK1 (ARK5) is associated with poor prognosis in ovarian cancer. Front Oncol 2016; 6: 213.

13 Chen P, Li K, Liang Y, Li L, Zhu X. High NUAK1 expression correlates with poor prognosis and involved in NSCLC cells migration and invasion. Exp Lung Res 2013: 39: 9-17.

14 Monteverde T, Muthalagu N, Port J, Murphy DJ. Evidence of cancer-promoting roles for AMPK and related kinases. FEBS J 2015; 282: 4658-4671.

15 Bell RE, Khaled M, Netanely D, Schubert S, Golan T, Buxbaum A et al. Transcription factor/microRNA axis blocks melanoma invasion program by miR-211 targeting NUAK1. J Invest Dermatol 2014; 134: 441-451.

16 Huang X, Lv W, Zhang JH, Lu DL. miR96 functions as a tumor suppressor gene by targeting NUAK1 in pancreatic cancer. Int J Mol Med 2014; 34: 1599-1605. 
17 Benaich N, Woodhouse S, Goldie SJ, Mishra A, Quist SR, Watt FM. Rewiring of an epithelial differentiation factor, miR-203, to inhibit human squamous cell carcinoma metastasis. Cell Rep 2014; 9: 104-117.

18 Shi L, Zhang B, Sun X, Lu S, Liu Z, Liu Y et al. MiR-204 inhibits human NSCLC metastasis through suppression of NUAK1. Br J Cancer 2014; 111: 2316-2327.

19 Xiong X, Sun D, Chai H, Shan W, Yu Y, Pu L et al. MiR-145 functions as a tumor suppressor targeting NUAK1 in human intrahepatic cholangiocarcinoma. Biochem Biophys Res Commun 2015; 465: 262-269.

20 Obayashi M, Yoshida M, Tsunematsu T, Ogawa I, Sasahira T, Kuniyasu H et al. microRNA-203 suppresses invasion and epithelial-mesenchymal transition induction via targeting NUAK1 in head and neck cancer. Oncotarget 2016; 7: 8223-8239.

21 Liu L, Ulbrich J, Muller J, Wustefeld T, Aeberhard L, Kress TR et al. Deregulated MYC expression induces dependence upon AMPK-related kinase 5. Nature 2012; 483: 608-612.

22 Ross FA, Mackintosh C, Hardie DG. AMP-activated protein kinase: a cellular energy sensor that comes in 12 flavours. FEBS J 2016; 283: 2987-3001.

23 Hanahan D, Weinberg RA. Hallmarks of cancer: the next generation. Cell 2011; 144: 646-674.

24 Shaw RJ, Kosmatka M, Bardeesy N, Hurley RL, Witters LA, DePinho RA et al. The tumor suppressor LKB1 kinase directly activates AMP-activated kinase and regulates apoptosis in response to energy stress. Proc Natl Acad Sci USA 2004; 101: 3329-3335.

25 Woods A, Dickerson K, Heath R, Hong SP, Momcilovic M, Johnstone SR et al. Ca2 +/calmodulin-dependent protein kinase kinase-beta acts upstream of AMPactivated protein kinase in mammalian cells. Cell Metab 2005; 2: 21-33.

26 Hawley SA, Pan DA, Mustard KJ, Ross L, Bain J, Edelman AM et al. Calmodulindependent protein kinase kinase-beta is an alternative upstream kinase for AMPactivated protein kinase. Cell Metab 2005; 2: 9-19.

27 Hardie DG, Alessi DR. LKB1 and AMPK and the cancer-metabolism link-ten years after. BMC Biol 2013; 11: 36

28 Hawley SA, Fullerton MD, Ross FA, Schertzer JD, Chevtzoff C, Walker KJ et al. The ancient drug salicylate directly activates AMP-activated protein kinase. Science 2012; 336: 918-922.

29 Banerjee S, Buhrlage SJ, Huang HT, Deng X, Zhou W, Wang J et al. Characterization of WZ4003 and HTH-01-015 as selective inhibitors of the LKB1-tumoursuppressor-activated NUAK kinases. Biochem J 2014; 457: 215-225.

30 Walz S, Lorenzin F, Morton J, Wiese KE, von Eyss B, Herold S et al. Activation and repression by oncogenic MYC shape tumour-specific gene expression profiles. Nature 2014; 511: 483-487.

31 Aderem A. The MARCKS brothers: a family of protein kinase $C$ substrates. Cell 1992; 71: 713-716.

32 Martiny-Baron G, Kazanietz MG, Mischak H, Blumberg PM, Kochs G, Hug H et al. Selective inhibition of protein kinase C isozymes by the indolocarbazole Go 6976. J Biol Chem 1993; 268: 9194-9197.

33 Adey A, Burton JN, Kitzman JO, Hiatt JB, Lewis AP, Martin BK et al. The haplotyperesolved genome and epigenome of the aneuploid HeLa cancer cell line. Nature 2013; 500: 207-211.

34 Fisher JS, Ju JS, Oppelt PJ, Smith JL, Suzuki A, Esumi H. Muscle contractions, AICAR, and insulin cause phosphorylation of an AMPK-related kinase. Am J Physiol Endocrinol Metab 2005; 289: E986-E992.

35 Gwinn DM, Shackelford DB, Egan DF, Mihaylova MM, Mery A, Vasquez DS et al. AMPK phosphorylation of raptor mediates a metabolic checkpoint. Mol Cell 2008; 30: 214-226.

36 Vincent EE, Coelho PP, Blagih J, Griss T, Viollet B, Jones RG. Differential effects of AMPK agonists on cell growth and metabolism. Oncogene 2015; 34: 3627-3639.

$37 \mathrm{Li} \mathrm{RJ}, \mathrm{Xu} \mathrm{J,} \mathrm{Fu} \mathrm{C,} \mathrm{Zhang} \mathrm{J,} \mathrm{Zheng} \mathrm{YG,} \mathrm{Jia} \mathrm{H} \mathrm{et} \mathrm{al.} \mathrm{Regulation} \mathrm{of} \mathrm{mTORC1} \mathrm{by}$ lysosomal calcium and calmodulin. Elife 2016. 5: doi:10.7554/eLife.19360.001.

38 Cermelli S, Jang IS, Bernard B, Grandori C. Synthetic lethal screens as a means to understand and treat MYC-driven cancers. Cold Spring Harb Perspect Med 2014; 4. doi:10.1101/cshperspect.a014209.

39 Shackelford DB, Shaw RJ. The LKB1-AMPK pathway: metabolism and growth control in tumour suppression. Nat Rev Cancer 2009; 9: 563-575.

40 Goodwin JM, Svensson RU, Lou HJ, Winslow MM, Turk BE, Shaw RJ. An AMPKindependent signaling pathway downstream of the LKB1 tumor suppressor controls Snail1 and metastatic potential. Mol Cell 2014; 55: 436-450.

41 Hoyer-Hansen M, Bastholm L, Szyniarowski P, Campanella M, Szabadkai G, Farkas $T$ et al. Control of macroautophagy by calcium, calmodulin-dependent kinase kinase-beta, and Bcl-2. Mol Cell 2007; 25: 193-205.

42 Fogarty S, Hawley SA, Green KA, Saner N, Mustard KJ, Hardie DG. Calmodulindependent protein kinase kinase-beta activates AMPK without forming a stable complex: synergistic effects of Ca2+ and AMP. Biochem J 2010; 426: 109-118.
43 Reihill JA, Ewart MA, Hardie DG, Salt IP. AMP-activated protein kinase mediates VEGF-stimulated endothelial NO production. Biochem Biophys Res Commun 2007; 354: 1084-1088.

44 Carling D, Sanders MJ, Woods A. The regulation of AMP-activated protein kinase by upstream kinases. Int J Obes (Lond) 2008; 32(Suppl 4): S55-S59.

45 Popovics P, Frigo DE, Schally AV, Rick FG. Targeting the 5'-AMP-activated protein kinase and related metabolic pathways for the treatment of prostate cancer. Expert Opin Ther Targets 2015; 19: 617-632.

46 Miranda F, Mannion D, Liu S, Zheng Y, Mangala LS, Redondo C et al. Salt-inducible kinase 2 couples ovarian cancer cell metabolism with survival at the adipocyterich metastatic niche. Cancer Cell 2016; 30: 273-289.

47 Drexler HG, Janssen JW, Brenner MK, Hoffbrand AV, Bartram CR. Rapid expression of protooncogenes c-fos and c-myc in B-chronic lymphocytic leukemia cells during differentiation induced by phorbol ester and calcium ionophore. Blood 1989; 73: 1656-1663.

48 Conacci-Sorrell M, Ngouenet C, Eisenman RN. Myc-nick: a cytoplasmic cleavage product of Myc that promotes alpha-tubulin acetylation and cell differentiation. Cell 2010; 142: 480-493.

49 Raffeiner P, Schraffl A, Schwarz T, Rock R, Ledolter K, Hartl M et al. Calciumdependent binding of Myc to calmodulin. Oncotarget 2017; 8: 3327-3343.

50 Habib T, Park H, Tsang M, de Alboran IM, Nicks A, Wilson L et al. Myc stimulates B lymphocyte differentiation and amplifies calcium signaling. J Cell Biol 2007; 179: 717-731

51 Evan Gl, Christophorou M, Lawlor EA, Ringshausen I, Prescott J, Dansen T et al. Oncogene-dependent tumor suppression: using the dark side of the force for cancer therapy. Cold Spring Harb Symp Quant Biol 2005; 70: 263-273.

52 Murphy DJ, Junttila MR, Pouyet L, Karnezis A, Shchors K, Bui DA et al. Distinct thresholds govern Myc's biological output in vivo. Cancer Cell 2008; 14: 447-457.

53 Reyland ME. Protein kinase C and apoptosis. In: Srivastava S (ed.). Apoptosis, Cell Signaling, and Human Diseases: Molecular Mechanisms. Humana Press: Totowa, NJ, Vol. 2, 2007, pp 1-55.

54 Whelan RD, Kiley SC, Parker PJ. Tetradecanoyl phorbol acetate-induced microtubule reorganization is required for sustained mitogen-activated protein kinase activation and morphological differentiation of U937 cells. Cell Growth Differ 1999; 10: 271-277.

55 Shen L, Dean NM, Glazer RI. Induction of p53-dependent, insulin-like growth factorbinding protein-3-mediated apoptosis in glioblastoma multiforme cells by a protein kinase Calpha antisense oligonucleotide. Mol Pharmacol 1999; 55: 396-402.

56 Graff JR, McNulty AM, Hanna KR, Konicek BW, Lynch RL, Bailey SN et al. The protein kinase Cbeta-selective inhibitor, Enzastaurin (LY317615.HCl), suppresses signaling through the AKT pathway, induces apoptosis, and suppresses growth of human colon cancer and glioblastoma xenografts. Cancer Res 2005; 65: 7462-7469.

57 Barr LF, Campbell SE, Baylin SB. Protein kinase C-beta 2 inhibits cycling and decreases c-myc-induced apoptosis in small cell lung cancer cells. Cell Growth Differ 1997; 8: 381-392.

58 Li W, Zhang J, Flechner L, Hyun T, Yam A, Franke TF et al. Protein kinase C-alpha overexpression stimulates Akt activity and suppresses apoptosis induced by interleukin 3 withdrawal. Oncogene 1999; 18: 6564-6572.

59 Partovian C, Simons M. Regulation of protein kinase B/Akt activity and Ser473 phosphorylation by protein kinase Calpha in endothelial cells. Cell Signal 2004; 16: 951-957.

60 Kawakami Y, Nishimoto H, Kitaura J, Maeda-Yamamoto M, Kato RM, Littman DR et al. Protein kinase $C$ betall regulates Akt phosphorylation on Ser-473 in a cell type- and stimulus-specific fashion. J Biol Chem 2004; 279: 47720-47725.

61 Zhang X, Tang N, Hadden TJ, Rishi AK. Akt, FoxO and regulation of apoptosis. Biochim Biophys Acta 2011; 1813: 1978-1986.

62 Delbridge AR, Strasser A. The BCL-2 protein family, BH3-mimetics and cancer therapy. Cell Death Differ 2015; 22: 1071-1080.

63 Muthalagu N, Junttila MR, Wiese KE, Wolf E, Morton J, Bauer B et al. BIM is the primary mediator of MYC-induced apoptosis in multiple solid tissues. Cell Rep 2014; 8: 1347-1353.

64 Li B, Simon MC. Molecular pathways: targeting MYC-induced metabolic reprogramming and oncogenic stress in cancer. Clin Cancer Res 2013; 19: 5835-5841.

This work is licensed under a Creative Commons Attribution 4.0 International License. The images or other third party material in this article are included in the article's Creative Commons license, unless indicated otherwise in the credit line; if the material is not included under the Creative Commons license, users will need to obtain permission from the license holder to reproduce the material. To view a copy of this license, visit http://creativecommons.org/licenses/ by/4.0/

(c) The Author(s) 2018

Supplementary Information accompanies this paper on the Oncogene website (http://www.nature.com/onc) 